\title{
A VIDA COMO OBRA DE ARTE: SABERES E FAZERES DO CAMPONÊS - MÃOS QUE MEDEM E LUTAM
}

\author{
Cláudia Glavam DUARTE ${ }^{\mathbf{1}}$ \\ Universidade Federal do Rio Grande do Sul \\ claudiaglavam@hotmail.com \\ Juliano Espezim Soares FARIA ${ }^{2}$ \\ Universidade Federal de Santa Catarina \\ juliano.espezim@ufsc.br
}

Resumo: Neste texto, pensando na possibilidade de tomar a vida como obra de arte, damos visibilidade as formas de vida de alguns sujeitos do campo: os pescadores artesanais Anastácio, Joaquim, Bino e a tecelã Romilda. Baseados no referencial teórico da Etnomatemática a partir do uso de elementos das propostas teóricas do segundo Wittgenstein, de Foucault e de Deleuze mostramos as racionalidades quantitativas das quais estes sujeitos se utilizam, e que evidenciam unidades de sentido distintas da racionalidade matemática hegemônica. Além de apresentar as formas de vida destes sujeitos do campo, damos continuidade à nossa tarefa de problematizar a universalidade e a neutralidade da matemática, mostrando que existem outras formas de matematizar a vida.

Palavras-chave: $\quad$ Etnomatemática; Educação do Campo; Pós-Estruturalismo.

\begin{abstract}
In this text, thinking about the possibility of taking life as a work of art, we give visibility to life forms of some subjects from the rural areas: the artisanal fishermen Anastacio, Joaquim, Bino and the weaver Romilda. Based on the theoretical framework of Ethnomathematics from and with the use of elements of the theoretical proposals of the second Wittgenstein, Foucault and Deleuze we showed the quantitatives rationalities used by these subjects, and we show units sense distinct of hegemonic mathematical rationality. In addition to presenting the ways of life of these subjects in the field, we continue our task of questioning the universality and neutrality of mathematics, showing that there are other ways to mathematizing the life.
\end{abstract} Education; Post-Estruturalism.
Key words: Ethnomathematics; Rural

\footnotetext{
${ }^{1}$ Doutorado em Educação pela Universidade do Vale do Rio dos Sinos, Brasil(2009). Professora ajunto III da Universidade Federal do Rio Grande do Sul , Brasil

${ }^{2}$ Mestrado em Educação pela Universidade Federal de Santa Catarina, Brasil(2011). Professor Assistente - A da Universidade Federal de Santa Catarina , Brasil
} 
[...] encontro gente que não sabe ler livros. Mas que sabe ler o seu mundo. Nesse universo de outros saberes, sou eu o analfabeto. Não sei ler sinais da terra, das árvores e dos bichos. Não sei ler as nuvens, nem o prenúncio das chuvas. [...]. Neste território, eu não tenho apenas sonhos. Eu sou sonhável. (MIA COUTO, 2011, p.14,15).

O que me surpreende, em nossa sociedade, é que a arte se relacione apenas com objetos e não com indivíduos ou a vida; e que também seja um domínio especializado, um domínio de peritos, que são os artistas. Mas a vida de todo indivíduo não poderia ser uma obra de arte? Por que uma mesa ou uma casa são objetos de arte, mas nossas vidas não? (FOUCAULT, 1994, p. 617)

Este texto emerge de nossos encontros ${ }^{3}$ com "gente que não sabe ler livros. Mas que sabe ler o seu mundo" e que, através de sua oralidade minimizaram nosso analfabetismo frente aos sinais da terra, do mar e da "luta com a lã". Foram encontros de ex-posição, no sentido dado por Larrosa (2002), nos quais pudemos apreender outras lógicas, no caso específico deste artigo, outras racionalidades matemáticas e, em efeito outros modos de perceber e estar no mundo.

\section{O solo teórico das investigações}

O que subsidia nosso diálogo nestes encontros que experenciamos advém das discussões propostas pela vertente educacional denominada Etnomatemática, originada na década de 70 quando o educador brasileiro Ubiratan D'Ambrosio inicia suas primeiras teorizações. Em uma entrevista (CHASSOT; KNIJNIK, 1997), D’Ambrosio comenta que o início de suas reflexões sobre este campo de estudos ocorreu quando era diretor do Programa de Pós-Graduação em Matemática na State University of New York at Buffalo. Nesta ocasião, o autor refere-se ao maior desafio de sua carreira administrativa: concretizar a política afirmativa de disponibilizar, para alunos negros, $25 \%$ das vagas do Programa que dirigia. Para cumprir tal desafio, D’Ambrosio percorre o sul daquele país em busca de tais estudantes. Segundo seu relato, através deste episódio, foi possível conhecer

[...] uma nova realidade americana, sobretudo a realidade das escolas e universidades discriminadas. Acredito que, então, surgiu o germe das minhas reflexões sobre uma Educação ligada à cultura. Minhas reflexões

\footnotetext{
${ }^{3}$ Os encontros aqui descritos e analisados são resultados de Trabalhos de Conclusão do curso em Licenciatura em Educação do Campo da - UFSC que foram por nós orientados. O primeiro a ser analisado foi realizado pela acadêmica Vera Lucia Costa (2014) e o segundo foi produzido por Ely das Graças Souza (2013).
} 
sobre a Etnomatemática, inclusive, vêm desta experiência. (CHASSOT; KNIJNIK, 1997, p. 13).

Sobre a origem da expressão Etnomatemática, D’Ambrosio (2002, p. 14) afirma que, "ao utilizar, num verdadeiro abuso etimológico, as raízes tica, matema e etno, dei origem à minha conceituação de Etnomatemática". Para este autor, "Etnomatemática é a arte ou técnica $($ techné $=$ tica) de explicar, de entender, de se desempenhar na realidade (matema), dentro de um contexto cultural próprio (etno)" (D’AMBROSIO, 1993, p. 5). Nesta perspectiva, a Etnomatemática procura resgatar, analisar e valorizar o saber e o fazer matemático produzido em diferentes contextos culturais, os quais não se referem unicamente a grupos étnicos,

No livro intitulado Etnomatemática em Movimento (KNIJNIK et al, 2012), as autoras apresentam um panorama desta vertente da Educação Matemática, levando em consideração sua emergência, passando pelo seu desenvolvimento e críticas sofridas, até seus novos olhares na contemporaneidade, os quais dizem respeito à produção de "deslocamentos" no que foi idealizado por D'Ambrosio. Tais deslocamentos consistem em mudanças de posições, mas que não neutralizam o imaginado inicialmente à Etnomatemática, contudo indicam outras formas de criar condições de visibilidade aos estudos ligados a este programa. A proposta das autoras permite escrever sobre a Etnomatemática de forma diferente apresentando outras maneiras de tratá-la em espaços educacionais, no que se refere à marginalização de determinados conteúdos e no reaparecimento de determinados saberes. (KNIJNIK et al, 2012, p. 13).

Os deslocamentos que as autoras apresentam dizem respeito às contribuições provenientes das teorizações do filósofo Ludwig Wittgenstein, mais especificamente as que estão presentes na obra Investigações Filosóficas cujos estudos tratam a linguagem como não possuidora de caracteres universais, de perfeição e de ordem, preexistentes às ações humanas, passando, assim, a considerar várias racionalidades (KNIJNIK et al, 2012, p. 28-31), além das de Foucault, autor que permite inserir a discussão sobre o disciplinamento e insurreição dos saberes. Além destes filósofos mencionados pelas autoras, propomos o uso dos escritos de Gilles Deleuze, no que tange a criação conceitual e que será tratado especificamente quando da apresentação de um dos trabalhos que serão aqui expostos.

As teorizações propostas por Wittgenstein têm contribuído, de forma ímpar, para problematizar o caráter universal pretendido pela matemática acadêmica e, em efeito, alicerçar as afirmações a respeito da existência de diversas matemáticas. Esta contribuição foi possibilitada pelo seu entendimento de racionalidade que se afasta da busca pela fundamentação última proveniente tanto de posturas essencialistas, que almejam uma essência lógica (idealista), quanto daquelas que buscam a positividade dos fatos (positivista). Wittgenstein problematiza, dessa forma, a racionalidade como resultado de um modelo representacional da linguagem - que propunha um isomorfismo entre linguagem e mundo.

MARGENS - Revista Interdisciplinar Versão Digital - ISSN: 1982-5374
10 anos de Margens-Dossiê: Olhares para o campo... VOL.10. N. 15. Dez 2016. (p. 150-160) 
De forma contrária, suas teorizações privilegiam a interação ao invés da representação, ou seja, a racionalidade para este filósofo emerge da gramática, das regras presentes nas interações dos jogos de linguagem, das práticas sociais cotidianas presentes em uma dada forma de vida. Como existem diferentes formas de vida com diferentes jogos de linguagem é possível inferir a existência de diferentes gramáticas que, consequentemente, possibilitam a construção de diferentes racionalidades. Neste sentido, temos identificado e analisado, especificamente os jogos de linguagem que se referem à matemática, presentes em diferentes formas de vida.

A filosofia wittgensteiniana da segunda fase desestabiliza desta forma, a compreensão da linguagem enquanto representação do mundo, ou seja, implica em um profundo questionamento e uma crítica ao paradigma da representação, seja ele proveniente de uma concepção metafísica ou empirista. Dito de outra forma, para este filósofo aquilo que conhecemos e damos significados, não está no objeto em si, fruto de uma essência, intenção esta do idealismo, nem na positividade dos fatos, justificativa do empirismo. Nesta perspectiva, sua concepção de linguagem afirma não existir

[...] a linguagem, mas simplesmente linguagens, isto é, uma variedade imensa de usos, uma pluralidade de funções ou papéis que poderíamos compreender como jogos de linguagem. Entretanto, como também não há uma função única ou privilegiada que possa determinar algum tipo de essência da linguagem, não há também algo que possa ser a essência dos jogos de linguagem. (WITTGENSTEIN APUD CONDÉ, 1998, p. 86, grifos do autor).

Wittgenstein, ao afirmar a inexistência de uma essência da linguagem, admite que nenhuma linguagem pode pretender-se universal. Existem linguagens e lógicas particulares, e estas são fruto do contexto onde estão inseridas. Nesta perspectiva, a obra de Wittgenstein fornece a possibilidade de questionarmos a pretensão de universalidade da linguagem da matemática acadêmica.

Com relação a Michel Foucault, fazemos destaque ao disciplinamento dos saberes e à insurreição dos saberes sujeitados. Para problematizar o progresso as Luzes, este filósofo nos põe a par do que chamou de o problema do saber técnico, ocorrido no século XVIII, período em que este emerge e funciona de forma dispersa, isto é, possui características regionais, que levam em conta elementos geográficos e específicos das empresas e oficinas, o que configurava um espaço constante de segredo e luta pelo saber. Com o desenvolvimento das forças de produção e das demandas econômicas, a luta travada por estes saberes tornouse mais intensa, o que implicou na apropriação dos saberes mais locais, artesanais, pelos saberes mais gerais, mais industriais. Esta apropriação é chamada por Foucault de disciplinamento dos saberes (FOUCAULT, 2010, p. 151-152).

Este disciplinamento é constituído de quatro procedimentos, dos quais o primeiro é o da seleção, responsável por desqualificar os pequenos saberes por serem considerados 
inúteis, custosos e irredutíveis. O segundo é a normalização pela qual estes saberes são sistematizados, estabelecendo uma comunicação entre eles, inclusive com o saber hegemônico, o científico. O terceiro é a hierarquização que parte destes saberes subordinados até o saber científico, estabelecendo uma classificação. E, finalmente, o quarto procedimento é a centralização que assegura as seleções e garante a transmissão hierárquica dos saberes na forma piramidal (FOUCAULT, 2010, p. 152) ${ }^{4}$.

Levando em consideração as ferramentas teóricas disponibilizadas por Foucault e Wittgenstein, orientamos trabalhos de conclusão de curso que buscam, cada um à sua maneira, produzir fissuras neste disciplinamento problematizando, junto com os alunos, a existência de saberes que ficaram marginalizados e que são, muitas vezes ignorados na academia.

\section{O primeiro encontro: Anastácio, Joaquim, Bino - Os Pescadores artesanais.}

Nossa iniciação no mundo da pesca foi realizada com pescadores artesanais da localidade de Ibiraquera, município de Imbituba, em Santa Catarina. Tal investigação teve como objetivo mapear algumas práticas desenvolvidas por pescadores artesanais de Ibiraquera e identificar a racionalidade matemática que as sustentam. Foram analisadas três práticas realizadas por estes pescadores: a utilização do corpo como unidade de medida, o cálculo do preço e do peso do peixe e a divisão do pescado que é feita entre os pescadores e ajudantes. Neste artigo daremos ênfase às unidades de medida utilizadas pelos pescadores, pois como afirmou um dos entrevistados: Mas, por que você acha que Deus fez estas marcas aí na sua mão? Foi para medir!

Costa (2014) afirma que nos relatos dos pescadores deparou-se com diversos conceitos matemáticos relacionados a sistemas de medidas, sobretudo na confecção da tarrafa. Seu Anastácio, 80 anos, um dos mestres de pesca da Praia do Rosa, referiu-se a utilização destas unidades de medida conforme excerto abaixo:

Aprendi com meus pais a fazer a tarrafa. Tarrafa para camarão, tarrafa para tainhota e tarrafa para tainha. Cada tarrafa faz o seu trabalho. A de camarão é uma malha e é uma grossura, a da tainha também é outra malha e é outra grossura de fio e a da tainhota também é outra grossura e outra malha. Uma tarrafa para camarão, tem uma malha de $3 \mathrm{~cm}$, para tainhota $4,5 \mathrm{~cm}$ e para tainha $6 \mathrm{~cm}$. A tarrafa é armada com 40 malha e pode terminar com $400 \mathrm{ou}$ até 1.000 malhas. Estas malhas eram medidas a dedo, pois naquele tempo não se usava metro. Assim, uma Cabecinha de dedo minguinho era o camarão que daria $3 \mathrm{~cm}$. Duas pontas de dedo para tainhota e 4 pontas de dedos para tainha. Era tudo medido a mão, a medida era os dedo. Depois passava para palmo e depois para braça.

\footnotetext{
${ }^{4}$ Faria (2013) trata de uma experiência pessoal de relação com a cubagem da terra, a qual analisa com base no disciplinamento dos saberes.
} 
Seu Joaquim, 60 anos, ao contrário de seu Anastácio, nunca foi dono de parelha (canoa), nem patrão. Quando pescava tainha, ficava no rancho, entre os camaradas e uma de suas atividades era confeccionar a tarrafa, o que faz até hoje. Sentado no pátio de sua casa, numa conversa descontraída numa tarde de inverno, enquanto manejava com agilidade as agulhas que teciam a tarrafa, ele explicou a diferença entre tarrafa e rede.

Uma tarrafa o máximo que pode chegar é 20 braças. Depois disso já é rede. Tem tarrafa para pescar na lagoa e para pescar no mar. Tem várias tarrafas e não é pouco. A tarrafa a gente usa para tarrafear de noite na guasca (tarrafear de noite na praia) e a rede para cercar peixes grandes, como tainha e anchova.

Seu Bino, 50 anos, pescador do mar e da lagoa, é dono de uma canoa e seu rancho fica na Praia Vermelha. Filho e neto de pescador, tudo que sabe aprendeu com seu pai.

A tarrafa nós armava ela com 50 e 60 malha em cima e vem fazendo os acrescentes pra baixo e depois quando ela tiver uma braça ou uma braça e meia, mais ou menos de acrescentes, bota o pano liso mais uma braça e meia para baixo. A malha tem de $3 \mathrm{~cm}$, de $5 \mathrm{~cm}, 6 \mathrm{~cm}$ e $7 \mathrm{~cm}$ ate $9 \mathrm{~cm}$ para tainha. A malha era medida com o metro. Os antigos usavam os dedos, já tinham as medidas certas. Nós hoje é com o metro.

É possível perceber que para estas comunidades muitas das unidades de medida utilizadas tomam como comparativo o corpo do próprio pescador. A exatidão e o formalismo, tão caro a matemática acadêmica são substituídas por um jogo de linguagem próprio da comunidade. No entanto, a gramática presente nos jogos de linguagem de uma forma de vida não se constitui em um sistema hermético. Esta não é própria ou exclusiva de uma dada forma de vida. Inversamente, a gramática constitui-se em um sistema aberto, flexível e dinâmico. Neste sentido, percebemos a interlocução entre sistemas que utilizam o corpo do pescador e o sistema de medidas decimal.

Os encontros que vêm sendo realizados pelos alunos do curso de Licenciatura em Educação do Campo, além de evidenciar gramáticas e formas de inteligibilidades diferenciadas no que se refere a modos de matematizar o mundo, têm também contribuído para reflexões no campo educacional. Tais reflexões vão desde a possibilidade de uma incursão mais densa na própria cultura, até a problematização dos sentidos e significados construídos para o aprender e o ensinar. Para o campo da educação matemática, destacamos a problematização da suposta neutralidade e "assepsia" pretendida pela Matemática, a dicotomia entre alta e baixa cultura, a diferença entre os problemas escolares e os problemas da vida real e, principalmente sobre o que conta como válido e legítimo para pertencer ao currículo de Matemática.

MARGENS - Revista Interdisciplinar Versão Digital-ISSN: 1982-5374
10 anos de Margens-Dossiê: Olhares para o campo... VOL.10. N. 15. Dez 2016. (p. 150-160) 


\section{O segundo encontro: Dona Romilda - a tecelã}

O segundo encontro diz respeito ao trabalho de tecelagem de Dona Romilda, quilombola da Invernada dos Negros, localizada em Campos Novos, Santa Catarina. O objetivo principal foi o de mostrar todas as etapas elaboradas pela protagonista do trabalho, teorizando-as a partir da potência encontrada na criação conceitual, recurso teórico deleuziano que, segundo Gallo (2008, p. 30) implica em roubar um conceito para produzir outro novo. Sobre este processo de criação conceitual, Tadeu, Corazza e Zordan (2004, p. 32) afirmam o seguinte:

O mais elevado poder do pensamento desta pesquisa é a criação, não a faculdade da verdade, digna do paradigma lógico-cognitivo ou racionalista, mas a do novo, a da criação de sentido, própria da filosofia. Desse modo, os "resultados" e os conceitos criados por ela são sempre verdadeiros, segundo a verdade que eles conseguem produzir, introduzir no mundo, atravessar, passar. Eles são sempre, portanto, "resultados" indiscutíveis, não-criticáveis, já que a sua rejeição em favor de outros resultadosconceitos tem sempre por condição outros problemas de pesquisa e outras imagens do pensamento.

O estudo da entrevista e das imagens obtidas permitiu que no trabalho de Souza (2013) fosse possível fazer furtar a organização das propriedades da Topologia das Superfícies ao ponto de considerar a atividade de Dona Romilda como um processo de deformação da lã. As especificidades das deformações que Dona Romilda imprime na lã permitiram criar variações de tais propriedades, as quais foram tratadas sob o nome de Topolãgia ${ }^{5}$. Tais deformações foram caracterizadas em quatro etapas: 1- A deformação da lã bruta em lã limpa, 2- A deformação da lã limpa em lã desfiada 3a- A deformação da lã desfiada em artesanato (acolchoado), 3b- A deformação da lã desfiada em fio e 4- A deformação do fio em artesanato (tapete, baixeiro, meia, etc.).

Todas estas propriedades que organizam o trabalho de Dona Romilda são caracterizadas por um termo usado por ela: a luta com a lã. Em um dos momentos da entrevista, referindo-se à professora de tecelagem que passou pela Invernada dos Negros, Dona Romilda afirma: "É que esse aqui ela não sabia. É que aqui é um trabalho mais antigo, ninguém usa mais. Tem gente que luta com lã mais com os outros, dai". As estações do ano também legitimam a possibilidade do uso do termo. Ao contar de seu trabalho com a lã programado para o inverno afirma: "Eu gosto de lutar mais no inverno com a lã que ela é muito quente". Assim, foi feita alusão ao processo de deformação da lã que é encolhida, esticada, fiada, entortada, recortada-colada, também, através do termo luta. Inclusive, a palavra vem ao encontro da intenção que temos com este trabalho, em lutar contra a

\footnotetext{
${ }^{5} \mathrm{O}$ acento tem o objetivo se fazer alusão à matéria-prima de Dona Romilda, mas o termo deve ser lido como uma paroxítona para que seja mantida a sonoridade do conceito furtado.
}

MARGENS - Revista Interdisciplinar Versão Digital - ISSN: 1982-5374
10 anos de Margens-Dossiê: Olhares para o campo... VOL.10. N. 15. Dez 2016. (p. 150-160) 
possibilidade de um disciplinamento do saber e, consequentemente, problematizar a universalidade e a neutralidade da matemática.

Fazemos destaque à confecção do acolchoado no qual a Topolãgia de Dona Romilda, apresenta uma identidade de superfície. Um exemplo desta identidade na Topologia das Superfícies é o que segue, no qual, a partir de dois círculos, é possível construir uma esfera, graças às propriedades do achatamento e colagem:

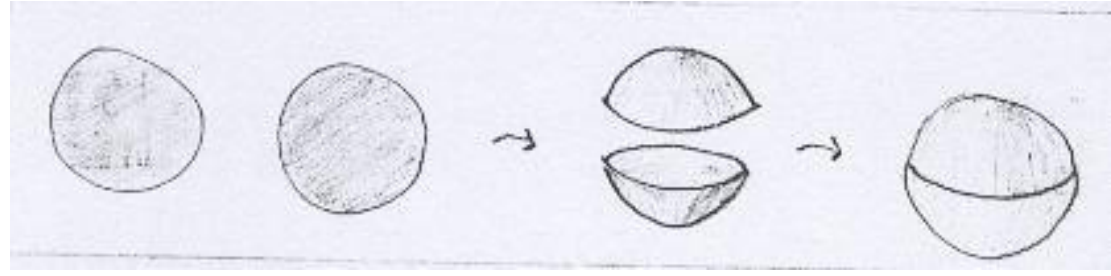

Fig. 1 - Superfícies via identificação

www.ime.usp.br/colli/Aderbal/Textos/Cap09/CapIXpg1.html

Dois círculos são deformados em duas meias esferas, as quais, juntas, formam uma esfera.

A Identidade de Superfície na Topolãgia que pode ser expressa por meio do seguinte diagrama, com o qual teríamos a seguinte representação:
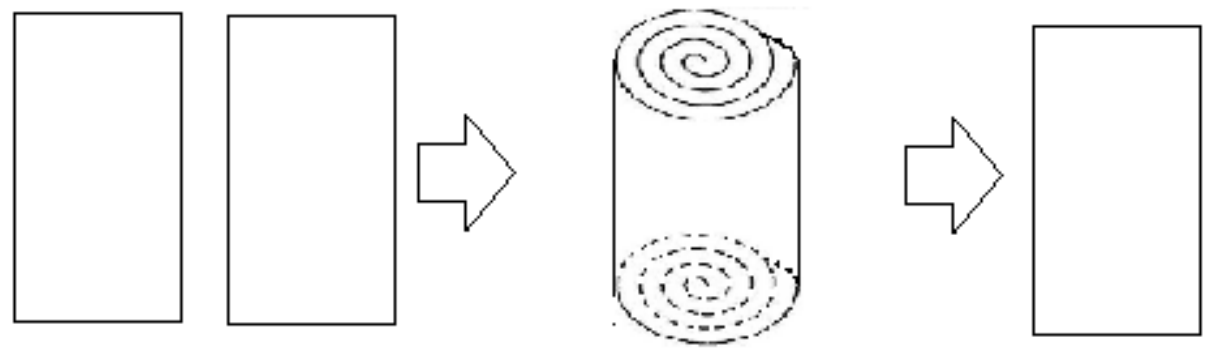

Fig. 2 - Transformação Topolãgica: lã e forro em acolchoado

Fonte: acervo dos autores

Os dois primeiros retângulos representam o forro do acolchoado e o bloco de lã. Assim, Dona Romilda constrói um bloco de lã sobre todo o avesso do forro sobrepondo-o. Depois, deforma estas duas superfícies enrolando-as, da parte fechada do forro para a parte aberta, formando um objeto que lembra um cilindro, mas seria mais fidedigno a um rocambole (imagem central). Na próxima etapa, pela abertura do forro é passado todo o volume do "cilindro" e o mesmo vai sendo desenrolado. Chegando ao final deste processo, o bloco de lã estará dentro do forro, ambos podendo ser representados por um objeto que lembra um único retângulo, representado pela última imagem da sequência. É uma estratégia engenhosa que favorece a alocação da lã de forma homogênea dentro do forro.

MARGENS - Revista Interdisciplinar

Versão Digital - ISSN: 1982-5374
10 anos de Margens-Dossiê: Olhares para o campo... VOL.10. N. 15. Dez 2016. (p. 150-160)

\section{7}


O outro tipo de deformação que a lã desfiada pode sofrer é o feitio do fio. Topolãgicamente falando, como uma massa de matéria prima virava um objeto "unidimensional"? Nesta etapa, Dona Romilda se utiliza do fuso, instrumento constituído de duas peças de madeira, um disco e um fino bastão que atravessa o centro do primeiro. Na extremidade do fuso mais distante do disco é amarrada a ponta da lã esticada e, ao ser posto em movimento, girando sobre seu próprio eixo, o fuso executa o processo de entortar a massa de lã e transformá-la em fio.

Outro elemento que a autora levanta acerca da Topolãgia é o fato desta, ao contrário da Topologia das Superfícies, não prevê o movimento inverso. A empiria do processo de trabalho de Dona Romilda, impede que seja possível a inversão do artesanato em lã no seu estado bruto. Topolãgia é flecha lançada.

De forma geral, as deformações da lã exigem um sequenciamento preciso das deformações: primeiramente, encolher, esticar, fiar. A partir deste ponto, com a lã fiada, há duas possibilidades: a) o feitio do acolchoado, que prevê recorte e "colagem" da lã ou b) deformação da lã em fio através do ato de entortar para fazer o artesanato. A Topolãgia, estudo das deformações que Dona Romilda imprime na lã, é acontecimento. Acontece respeitando as estações do ano, mas independente do período, este acontecimento se caracteriza por luta.

\section{Considerações Finais}

Pensamos que "olhar" para situações cotidianas, para situações já vividas e atribuir novos sentidos implica, no limite, escapar da captura de discursos hegemônicos no campo da Educação Matemática, construindo, desta forma, a possibilidade de um pensar movido por uma inquietação permanente. Neste sentido, as investigações e as práticas desenvolvidas na perspectiva acima apresentadas, inserem-se na árdua tarefa dos trabalhos que buscam desestabilizar o solo fixo das possibilidades de lidar com o conhecimento matemático, com a Educação Matemática e, principalmente, com modos de ser e tornar-se professor de matemática.

Neste sentido,

Não se trata, portanto, de glorificara matemática popular, celebrando-a em conferências internacionais, como uma preciosidade a ser conservada a qualquer custo. Esse tipo de operação não empresta nenhuma ajuda aos grupos subordinados. Enquanto intelectuais, precisamos estar atentos para não pô-la em execução, exclusivamente na busca de ganhos simbólicos no campo científico ao qual pertencemos. No entanto, também não se trata de negar à Matemática popular sua dimensão de autonomia... (KNIJNIK, 1996, p.278).

Objetivamos mostrar a originalidade das racionalidades do campo e mostrá-la como plenamente legítima no plano discursivo em que se insere. A operação de colocar alguma 
etnomatemática na mesma altura dos saberes matemáticos hegemônicos através de um recurso que exige condições de igualdade entre saberes, não corresponde à forma pela qual, neste caso, estamos mais próximos de Foucault (2011, p. 5), para quem, "aquilo que se deve ter como referência não é o grande modelo da língua ou dos signos, mas sim da guerra e da batalha". A harmonia que se busca entre os saberes quando se pensa em valorizar aqueles dos sujeitos do campo na escola, por exemplo, pode fazer parte de um sutil processo de disciplinamento de saber, isto é, ao considerar estes saberes como conteúdos a serem trabalhados na escola, corre-se o risco de colocá-los na maquinaria escolar, podendo implicar em suas capturas por todas as engrenagens próprias desse espaço: a linguagem, a divisão dos tempos e do espaço, entre outros, dando margem a um processo de normalização, isto é, estes saberes adentram esse espaço e ganham contornos de saber escolar, sendo descoladas de seu plano discursivo.

\section{Referências Bibliográficas}

CHASSOT, Attico; KNIJNIK, Gelsa. Conversando com Ubiratan D’Ambrosio. In: Episteme: filosofia e história das ciências em revista. ILEA/UFRGS, Porto Alegre, v. 2 n. 4, 1997.

CONDÉ, Mauro Lúcio Leitão. As teias da razão: Wittgenstein e a crise da racionalidade moderna. Belo Horizonte: Argvmentvm, 2004.

COSTA, Vera Lúcia. A Racionalidade matemática dos pescadores artesanais de IbiraqueraSC. 2014. Trabalho de Conclusão de Curso (Licenciatura em Educação do Campo) Universidade Federal de Santa Catarina.

D’AMBROSIO, Ubiratan. Etnomatemática: arte ou técnica de explicar e conhecer. 2.ed.São Paulo: Editora Ática, 1993.

D’AMBRÓSIO, Ubiratan. Etnomatemática. Elo entre as tradições e a modernidade. 2 ed. Belo Horizonte: Autêntica, 2002.

FARIA, Juliano. Espezim Soares. Etnomatemática e Educação do Campo: E agora, José?. In: Em Teia: Revista de Educação Matemática e Tecnológica Iberoamericana, v.4 n.3, Recife, 2013.

FOUCAULT, M. “À propos de la généalogie de l'éthique: un aperçu du travail en cours" (entrevista com H. Dreyfus e P. Rabinow, segunda versão) in Dits et écrits(19801988), IV, Paris: Gallimard, 1994, 609-631.

FOUCAULT, Michel. Em Defesa da Sociedade: curso no Collège de France (1975-1976); tradução Maria Ermantina Galvao. - 2a ed.-São Paulo: Editora WMF Martins Fontes, 2010.

MARGENS - Revista Interdisciplinar

Versão Digital - ISSN: 1982-5374
10 anos de Margens-Dossiê: Olhares para o campo... VOL.10. N. 15. Dez 2016. (p. 150-160) 
FOUCAULT, Michel. Microfísica do Poder. São Paulo: Edições Graal, 2011.

GALLO, Silvio. Deleuze \& a educação. Belo Horizonte: Autêntica, 2003.

KNIJNIK, Gelsa. Exclusão e Resistência: Educação Matemática e Legitimidade Cultural. Rio Grande do Sul. Artes Médicas. 1996.

KNIJNIK, Gelsa; WANDERER, Fernanda; GIONGO, Ieda; DUARTE, Cláudia Glavam. Etnomatemática em Movimento. Belo Horizonte: Autêntica, 2012.

LARROSA, Jorge Bondía. Notas sobre a experiência e o saber da experiência. Revista Brasileira de Educação, São Paulo, n 19, 2002. pp. 20-28.

SOUZA, Ely das Graças. Dona Romilda e sua Topolãgia: as deformações da lã de ovelha. 2013. Trabalho de Conclusão de Curso (Licenciatura em Educação do Campo) Universidade Federal de Santa Catarina.

TADEU, Tomaz; CORAZZA, Sandra; ZORDAN, Paola. Linhas de Escrita. Belo Horizonte: Autêntica, 2004.

WITTGENSTEIN, Ludwig. Investigações Filosóficas. 3.ed. Petrópolis: Vozes, 2004.

MARGENS - Revista Interdisciplinar

Versão Digital - ISSN: 1982-5374
10 anos de Margens-Dossiê: Olhares para o campo... VOL.10. N. 15. Dez 2016. (p. 150-160) 